\title{
EL MOVIMIENTO DE POBLADORES DURANTE LA UNIDAD POPULAR, 1970-1973*
}

\author{
THE SOCIAL MOVEMENT OF "POBLADORES" \\ DURING THE POPULAR UNITY, 1970-1973
}

\section{MARIO GARCÉS DURÁN**}

\section{RESUMEN}

En este artículo se sostiene que los más pobres de las ciudades chilenas, es decir los pobladores, incrementaron sus movilizaciones y demandas por viviendas, desde fines de los años sesenta y especialmente durante el gobierno de la Unidad Popular. Para ello contaron con sus propios esfuerzos de organización popular así como con el apoyo de los partidos políticos. El incremento de las movilizaciones de los pobladores así como la respuesta del Estado favoreció el surgimiento de nuevos barrios populares, que les permitió a los sujetos implicados en las movilizaciones modificar sus modos de habitar las principales ciudades del país.

Palabras clave: Pobladores, movilizaciones, organizaciones sociales.

\section{ABSTRACT}

This article argues that the urban poor in Chilean cities, los pobladores, expanded their mobilizations and demands for housing starting in the late 1960s but especially during the Popular Unity government (1970-1973). They did so through their own organizational efforts and popular organizations as well as in conjunction with political parties. Greater mobilization by pobladores coupled with the State's response favored the

${ }^{\star}$ Este artículo da cuenta de los resultados del Proyecto FONDECYT No 1100124, regular 2010. "El movimiento de pobladores durante la Unidad Popular: De las 'tomas de sitios' a la formación de 'poblaciones'”. Agradezco las contribuciones de Susana Costamagna y Marcelo Robles.

** Doctor en Historia, docente del Departamento de Historia de la Universidad de Santiago de Chile. Correo electrónico: mario.garces@usach.cl 
creation of new working-class neighborhoods, which permitted the individuals who mobilized to change their way of life in Chile's largest cities.

Keywords: Urban poor, mobilization, social organizations.

Recibido: 08.02.13. Aceptado: 22.08.13.

\section{INTRODUCCIÓN}

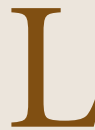

OS MÁS POBRES DE LA CIUDAD, es decir los pobladores, se constituyeron en los años sesenta en un movimiento social de alta significación en la sociedad, especialmente por sus demandas y luchas por la vivienda. Estas demandas, que recibían una mayor atención del Estado, luego de la creación del Ministerio de la Vivienda y Urbanismo, en 1965, se vieron fuertemente incrementadas en la coyuntura electoral de 1970, que llevó a la presidencia a Salvador Allende, así como durante el gobierno de la Unidad Popular. En esta etapa, los pobladores multiplicaron sus movilizaciones tanto en Santiago como las principales capitales de las provincias chilenas.

La hipótesis general que ha orientado nuestras indagaciones sostiene que entre los años 1967-1973, los pobladores ampliaron y extendieron sus capacidades y estructuras organizativas -a través de Comités de Sin Casa, pero también Centros de Madres y Juntas de Vecinos-; incrementaron sus movilizaciones y repertorios de acción, especialmente las "tomas de sitios", y contaron con aliados fundamentales en el sistema político -tanto entre los partidos políticos como en nuevas agencias estatales- para el logro de sus metas, la casa propia y la ampliación de las políticas estatales de viviendas y de urbanización. En este contexto, emergieron nuevos barrios populares, que transformaron la geografía urbana de las principales ciudades del país.

\section{LOS POBLADORES EN PERSPECTIVA HISTÓRICA}

La cuestión de la habitación popular precaria ha sido un viejo e histórico problema social de las ciudades latinoamericanas, prácticamente de origen colonial (Romero, 1999). En el caso de Santiago, en la segunda mitad del siglo XIX, la tendencia fue que se constituyera una ciudad segregada, en la que como indicó el historiador Armando de Ramón (2000), los pobres que inmigraban de las zonas rurales continuaran "instalándose en la periferia 
como había sido tradicional, aunque la mayoría cuando obtenían trabajo, se mudaban hacia el centro donde existían viviendas para ellos (...) los 'conventillos', construcciones compuestas por un patio o corredor en común y dos o más cuerpos de habitaciones, cada una de las cuales era alquilada por una familia diferente" (De Ramón, 2000, p. 191; Salazar, 2000, p. 232).

Por su parte, en un sentido más amplio, en América Latina no fue sino hasta mediados del siglo XX, y en particular en la fase "desarrollista", que las ciudades crecieron de tal manera que llegaron a hacer del "problema urbano", un problema social relevante, para varios países del continente (Halperin, 2008). Santiago de Chile, en las décadas del 30 al 70, no solo vio crecer a su población, como producto de la migración del campo a la ciudad, sino que empeoraron las condiciones de vida, ya críticas, de los más pobres. Así lo confirmó el Primer Censo Nacional de la Vivienda, de 1952, al establecer que, en el nivel nacional, un 30\% de la población carecía de viviendas adecuadas (Servicio Nacional de Estadísticas y Censos, 1952, p. I), guarismo que para Santiago subía el 36\%, lo que permitía establecer que un tercio de los santiaguinos subarrendaba, vivía en conventillos, poblaciones callampas, en viviendas en mal estado, o simplemente como "allegados"1.

Reconocida la gravedad del problema de la habitación popular, el Estado comenzó a jugar roles más activos, de tal forma que en 1953, se creó la Corporación de la Vivienda, CORVI, y se establecieron los primeros "planes nacionales" de construcción de viviendas, en la administración de Carlos Ibáñez. Estos planes tuvieron un bajo rendimiento, sobre todo con relación a los más pobres de la ciudad, que no reunían las condiciones mínimas de ingresos para postular a los planes de la CORVI, lo que revelaba que los problemas de la pobreza no solo se referían a la falta de vivienda, sino que a otros factores, como el bajo poder adquisitivo de los salarios y la inserción laboral inestable de los más pobres (Garcés, 2002).

Sin embargo, a los pocos años de fundada la CORVI, y habida cuenta de los límites de la política estatal, en octubre de 1957 se verificó una toma o invasión de sitios en la zona sur de Santiago, que comenzó a insinuar una nueva manera de posicionarse de los pobladores frente al Estado. En efecto, el 30 de octubre de ese año se verificó la toma de sitios que dio origen a la Población La Victoria, frente a la cual la primera reacción del gobierno fue de carácter policial -desalojar la toma, que violaba la ley-, no obstante, la acción represiva podía derivar en una masacre y mediando la acción de

\footnotetext{
1 "Allegados" se denominaba a las familias pobres, en muchos casos de nuevos inmigrantes, que eran acogidos por parientes o amigos, que les asignaban un espacio en sus viviendas.
}

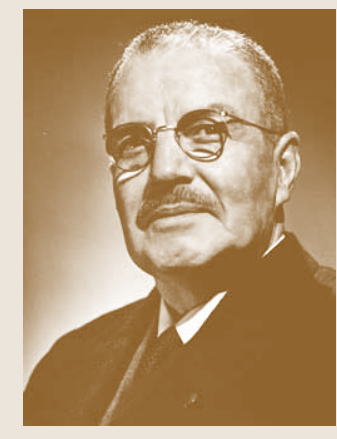

C. Ibáñez del Campo 


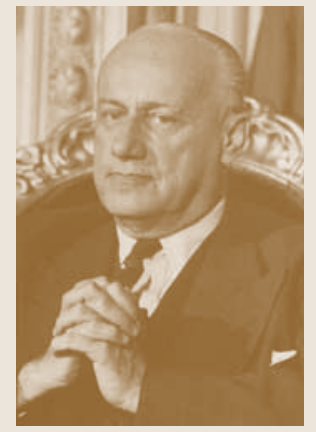

J. Alessandri

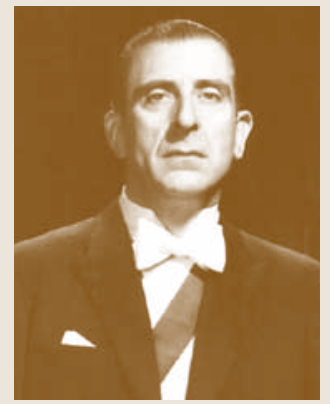

E. Frei Montalva los partidos políticos y la Iglesia Católica, el gobierno se allanó a permitir la permanencia de los pobladores en los sitios "tomados" (Espinoza, 1988; Farías, 1989). Ahora bien, cuando se observa en perspectiva, La Victoria estaba inaugurando, en 1957, una estrategia que iría ganando en prestigio y desarrollo en los años siguientes: si el Estado no atendía las demandas por vivienda de los pobladores, ellos mismos, organizadamente, podían tomar sitios y levantar sus propias poblaciones.

En líneas muy generales, entre 1957 y 1973, el proceso comprometió las políticas públicas de distintos gobiernos y también diversos ciclos de movilización popular. Luego del relativo fracaso de los planes de vivienda de Ibáñez y de los límites de la CORVI, la administración Alessandri dio lugar a nuevos planes de vivienda más masivos y de menor costo, conocidos como "soluciones habitacionales", erradicaciones de poblaciones callampas, con traslados masivos como el que llevó a la formación, en 1959, de la Población San Gregorio, para unos 20 mil habitantes y la Población José María Caro, en la que se distribuyeron 9 mil sitios para unas 60 mil personas. Estas medidas, que favorecieron el surgimiento de nuevos barrios populares, generaron, al mismo tiempo, grandes expectativas entre "los sin casa", lo que llevó a una nueva y simbólica "toma" en 1961, la de Santa Adriana, en la zona sur de Santiago, que desató una gran polémica pública en torno a la "legitimidad" de estas acciones en el Congreso Nacional (Garcés, 2002, p. 225).

La situación crítica de los más pobres, así como la presión de los pobladores, llevó a la administración democratacristiana, en 1964, a proponer no solo más ambiciosos planes de vivienda (construir 360 mil viviendas en seis años, destinando dos tercios de ellas para los más pobres) y apoyos concretos a los pobladores, a través de la agenda estatal -se creo la Consejería Nacional de Promoción Popular- sino que a la constitución del Ministerio de la Vivienda y Urbanismo (MINVU). Estas nuevas políticas públicas vendrían a modificar por completo las dinámicas de organización y presión popular, ya que se creaba un nuevo cuadro de oportunidades políticas; los pobladores contarían ahora con un interlocutor especializado en sus asuntos y demandas. La administración DC hizo significativos esfuerzos por cumplir con sus promesas, pero la demanda y la presión poblacional superó sus planes, de tal forma que a partir de marzo de 1967, cuando se produjo la emblemática toma de "Herminda de la Victoria", en el sector poniente de Santiago, las tomas de sitios y las peticiones por abrir nuevas "operaciones sitios" se multiplicaron: 13 tomas en 1967; 4 en 1968; 35 en 1969; y 103 en 1970, es decir 155 tomas de sitios en cuatro años (Castells, 
1973) $)^{2}$. A estas alturas, los pobladores habían constituido Comités de Sin Casa, por barrio, y en muchos casos, articulados en el nivel comunal, y el recurso de la "toma" como estrategia de presión y solución -inicial al menos- para la consecución de una vivienda, se mostraba altamente eficiente.

Cuando Allende asumió el gobierno, a fines de 1970, se estimaba que el déficit de viviendas todavía alcanzaba a 592 mil unidades (CORVI, 1972, p. 2), pero, además, la ciudad de Santiago se hallaba poblada de "campamentos", producto de "tomas de sitios" y de "Operaciones sitio" que se incrementaron en el trienio 1967-1970. Según informaciones del MINVU, en 1971 existían 238 campamentos en la capital, y se estimaba que en ellos habitaban unas 85 mil familias (CORVI, 1972). Los partidos de la Unidad Popular, especialmente comunistas y socialistas, habían estimulado y apoyado muchas "tomas de sitios" y Allende, en la campaña presidencial, se había comprometido a impulsar nuevas políticas de vivienda. De este modo, la Unidad Popular debía generar un programa muy activo y de gran magnitud para enfrentar el problema de la vivienda popular, el que tomó forma en el Plan de Emergencia de 1971. Este contempló, entre otras medidas, iniciar la construcción de 79 mil viviendas y la urbanización de 120 mil sitios, obras que efectivamente se iniciaron el año indicado, con resultados variables en cuantos al tiempo estimado, en especial para la construcción de viviendas definitivas (MINVU, 1972, p. 44). El Ministerio de la Vivienda se reestructuró, creándose un Subdepartamento de Campamentos; una Oficina del Poblador; y, además un Departamento de Ejecución Directa de obras de construcción.

\section{LOS POBLADORES DURANTE LA UNIDAD POPULAR: MOVILIZACIONES, ORGANIZACIONES, ALIANZAS}

Teniendo en cuenta que la mayor parte de los estudios sobre los pobladores se concentran en la ciudad de Santiago, hemos buscado dilucidar la magnitud y la naturaleza de las movilizaciones más allá de la capital, realizando un seguimiento de la prensa tanto en Santiago, como en Valparaíso y Concepción. Revisando los diarios Las Noticias de la Última Hora de Santiago,

\footnotetext{
${ }^{2}$ Los números de "tomas de sitios" son referenciales, ya que es difícil establecer con claridad un número exacto de este tipo de acciones, ya que unas tomas permanecían, otras eran desalojadas; otras trasladadas a sectores distintos a su lugar de origen.
} 
El Mercurio de Valparaíso y El Sur de Concepción ${ }^{3}$, hemos obtenido los siguientes resultados:

Cuadro 1. Movilizaciones de pobladores entre 1970 y 1973.

\begin{tabular}{|l|c|c|c|c|}
\hline & Valparaíso & Concepción & Santiago & Totales \\
\hline $\begin{array}{l}\text { Movilizaciones } \\
\text { de pobladores }\end{array}$ & 244 & 586 & 170 & 1.000 \\
\hline
\end{tabular}

Fuente: Elaboración propia sobre la base de los diarios El Mercurio de Valparaíso; El Sur de Concepción, Las Noticias de Última Hora, de Santiago.

Las movilizaciones, con un variado "repertorio de acciones", se orientaron a obtener viviendas, mediante "tomas" de terrenos u "operaciones sitio", precedidas de petitorios a la autoridad y seguidas de diversas formas de presión y negociación. En términos generales, luego de una "toma” y la formación de un "campamento", que fue el origen de muchas nuevas "poblaciones", le siguieron otro conjunto de movilizaciones orientadas a resolver problemas de urbanización e infraestructura (agua, luz, transporte, así como servicios de salud y educación).

Cuadro 2. Movilizaciones en Valparaíso, según objetivos 1970-73.

\begin{tabular}{|c|c|c|c|c|c|c|c|}
\hline Año & $\begin{array}{c}\text { Toma } \\
\text { sitio, } \\
\text { vda. }\end{array}$ & $\begin{array}{c}\text { Luchas por } \\
\text { la vda. y o } \\
\text { sitio }\end{array}$ & Transporte & urbanización & $\begin{array}{c}\text { Conflicto } \\
\text { intra- } \\
\text { pobladores }\end{array}$ & Abastecimiento & Otras \\
\hline 1970 & 2 & 0 & 2 & 14 & 2 & 0 & 8 \\
\hline 1971 & 22 & 1 & 7 & 23 & 2 & 2 & 14 \\
\hline 1972 & 3 & 3 & 7 & 37 & 8 & 3 & 13 \\
\hline 1973 & 1 & 0 & 7 & 32 & 5 & 18 & 8 \\
\hline Total & 28 & 4 & 23 & 106 & 17 & 23 & 43 \\
\hline
\end{tabular}

Total de movilizaciones, 1970-1973: 244.

Fuente: Elaboración propia sobre la base del diario El Mercurio de Valparaíso.

En el caso de Valparaíso, se verificó en la década del sesenta una activa política estatal encaminada a la construcción de viviendas, especialmente en los cerros de Viña del Mar (Granadillas, Forestal, Santa Julia) ya que

${ }^{3}$ El registro se realizó teniendo en cuenta los siguientes descriptores. Para consignar las movilizaciones distinguimos: 1 . Tomas de sitios; 2 . Lucha por la vivienda y Operación Sitio; 3. Transporte; 4. Urbanización; 5. Conflictos intrapobladores; 6. Abastecimiento; 7. Otros. Y, para el registro de los anuncios de Políticas Públicas, distinguimos cinco descriptores: 1. Vivienda; 2. Operación sitio, autoconstrucción, asignación de terrenos; 3. Urbanización; 4. Abastecimiento; 5. Otros. 
la ciudad puerto, salvo el sector de Playa Ancha, tenía límites físicos para una mayor expansión. Sin embargo, los problemas de urbanización estaban presentes en toda la región, tanto en los cerros de Valparaíso como en las nuevas zonas de "poblaciones" en Viña del Mar, lo que explica el mayor índice de movilizaciones en este ámbito.

Cuadro 3. Movilizaciones en Concepción, según objetivos 1970-1973.

\begin{tabular}{|c|c|c|c|c|c|c|c|}
\hline Año & $\begin{array}{c}\text { Toma } \\
\text { sitio, } \\
\text { vda. }\end{array}$ & $\begin{array}{c}\text { Luchas por } \\
\text { la vda. y o } \\
\text { sitio }\end{array}$ & transporte & urbanización & $\begin{array}{c}\text { Conflicto } \\
\text { intra- } \\
\text { pobladores }\end{array}$ & Abastecimiento & Otras \\
\hline 1970 & 35 & 38 & 0 & 38 & 12 & 0 & 12 \\
\hline 1971 & 117 & 27 & 0 & 40 & 5 & 5 & 24 \\
\hline 1972 & 12 & 21 & 5 & 47 & 8 & 24 & 27 \\
\hline 1973 & 8 & 11 & 5 & 12 & 17 & 28 & 8 \\
\hline Total & 172 & 97 & 10 & 137 & 42 & 57 & 71 \\
\hline
\end{tabular}

Total de movilizaciones, 1970-1973: 586.

Fuente: Elaboración propia en base al diario El Sur de Concepción.

En el caso de la región del Biobío, tanto en Concepción como en las ciudades y pueblos aledaños (Talcahuano, Chiguayante, Penco, Coronel, Lota) así como las ciudades de Los Ángeles y Chillán, el déficit de viviendas y la mayor presencia de organizaciones políticas de la Izquierda, en especial el Movimiento de Izquierda Revolucionaria (MIR), estimularon las "tomas de sitios", que alcanzaron el mayor número de iniciativas de movilización. Y de manera semejante a la región de Valparaíso, las demandas por urbanización también se multiplicaron, habida cuenta de la necesidad de dotar de servicios básicos a los nuevos asentamientos urbanos, que nacieron producto de las tomas y también de las "operaciones sitios" de fines de los años sesenta.

Cuadro 4. Movilizaciones en Santiago, según objetivos 1970-1973.

\begin{tabular}{|c|c|c|c|c|c|c|c|}
\hline Año & $\begin{array}{c}\text { Toma } \\
\text { sitio, } \\
\text { vda. }\end{array}$ & $\begin{array}{c}\text { Luchas } \\
\text { por la } \\
\text { vda. y o } \\
\text { sitio }\end{array}$ & Transporte & Urbanización & $\begin{array}{c}\text { Conflicto } \\
\text { intrapobladores }\end{array}$ & Abastecimiento & Otras \\
\hline 1970 & 12 & 28 & - & 5 & 3 & - & 2 \\
\hline 1971 & 3 & 14 & 2 & 2 & 2 & 2 & 25 \\
\hline 1972 & 1 & 7 & 2 & 3 & - & 19 & 9 \\
\hline 1973 & - & 1 & 1 & - & 1 & 19 & 8 \\
\hline Total & 16 & 50 & 5 & 10 & 6 & 40 & 44 \\
\hline
\end{tabular}

Total de movilizaciones, 1970-1973: 171.

Fuente: elaboración propia sobre la base del diario Las Noticias de Última Hora, Santiago. 
Para Santiago, los resultados que se indican en el cuadro son francamente parciales, ya que el nivel de movilizaciones es mucho mayor, si se tienen en cuenta otras fuentes, tanto de otros periódicos como estudios de la época. Sin embargo, este cuadro, nos permite identificar ciertas tendencias del movimiento, por ejemplo, la alta incidencia de "luchas por la vivienda y operaciones sitio" que se verificaron en el año 1970, que sumado a las tomas muestran a un movimiento de pobladores muy activo en sus demandas por vivienda. Los estudios de época contabilizaron las "tomas" en Santiago, entre 1967 y 1971 -Castells (1973) las estima en 155; Duque y Pastrana (1972) en 312-, mientras que una indagación reciente de Boris Cofré (2011) contabilizó 101 tomas entre 1971 y 1973. Si sumamos el dato de Castells con el de Cofré, se podría estimar que en Santiago se verificaron 256 tomas entre 1967 y 1973.

El seguimiento de las movilizaciones nos ha permitido, además, distinguir dos fases o dos tipos de movilizaciones de naturaleza diferente. Por una parte, las movilizaciones orientadas a la obtención de vivienda y equipamiento urbano, que si bien cubre todo el período, fueron especialmente activas entre 1970 y 1972. Por otra parte, a partir de 1972, es posible distinguir otra fase o ciclo de movilizaciones cuyo eje principal fue la cuestión del abastecimiento de productos de primera necesidad. Este fue un problema crítico, que movilizó y confrontó al conjunto de la población, tanto en relación a la resolución del problema como a propósito de sus causas y de sus efectos. Surgieron nuevas organizaciones, como las Juntas de Abastecimientos y Precios (JAP), Almacenes Populares o Comités de Distribución Directa, que fueron permanentemente objeto de disputas y polémica, en las que estaban implicados los pobladores, pero también vastos sectores de la población y los principales actores sociales y políticos de la época.

\section{LAS ORGANIZACIONES}

La organización de los pobladores ha sido, sin lugar a dudas, un soporte y un recurso fundamental en toda su historia. Desde que emergen en la escena pública -a fines de los años cincuenta- la organización fue el principal instrumento para movilizarse y materializar sus demandas por viviendas y un lugar en la ciudad. Pero, además, la organización fue también la principal forma de dar vida colectiva y comunitaria a las nuevas "poblaciones", constituyéndose ellas en espacios de participación y toma de decisiones. La organización entonces se revela en una doble perspectiva: como un "instru- 
mento de lucha", pero al mismo tiempo como un espacio para la construcción de un "poder local comunitario".

De acuerdo con los "ciclos de movilización", por un largo periodo centrado en la obtención de viviendas y más tarde por el abastecimiento, distinguimos las siguientes "estructuras organizativas".

a) Comités de Sin Casa y Juntas de Vecinos. En la fase expansiva del movimiento, los pobladores contaron con dos tipos de organización: Los Comités de Sin Casa o Comités de Vivienda y las Juntas de Vecinos y Centros de Madres, que se legalizaron en 1968. En las luchas por la vivienda pesaron más los Comités de Sin Casa. Estos podían surgir en el barrio, en el lugar de trabajo, de relaciones familiares o de amistad, y se multiplicaron territorialmente, con apoyo de partidos políticos, en el nivel comunal, por ejemplo, el Comando Comunal de los Sin Casa de Conchalí, que agrupaba a ocho Comités de Sin Casa, que sumaban 1500 familias, y que tomaron sitios en el sector de Guanaco en octubre de 1969 (Garcés, 1998, p. 56). También surgieron en zonas más amplias -la zona sur de Santiago- pero unificados y coordinados políticamente (las tomas del MIR, por ejemplo, en 1970, que dieron origen a cinco campamentos, 26 de Enero, Ranquil, Elmo Catalán, Magaly Honorado y 26 de Julio). Luego de la "toma", la asignación de sitios y la organización de la nueva población, la tendencia fue que se debilitaran los comités o las comisiones (de Vigilancia, Salud, etc.) de la etapa de Campamento, y se privilegiara la organización de una Junta de Vecinos. Sin embargo, algunos campamentos, de reciente fundación o que contaban con una dirección política más militante, tendieron a generar nuevos tipos de organización, por "frentes", para encarar la organización de la propia población (frentes o comisiones de Salud, Educación, Vigilancia, Construcción, etc.). La organización local, en estos casos, reforzó sus capacidades como un "poder local comunitario". Una experiencia emblemática, en este sentido, fue el Campamento Nueva Habana, ubicado en el sector oriente de la actual comuna de La Florida (Leiva, 2002; Cofré, 2007).

b) Juntas de Abastecimiento y Control de Precios (JAP) y Almacenes Populares. A partir de mediados de 1972, la situación de desabastecimiento de productos básicos se constituyó en un problema crucial. Para encarar esta nueva situación surgieron dos tipos de organizaciones: las Juntas de Abastecimiento y Control de Precios (JAP) promovidas por el gobierno y fuertemente estimuladas por el Partido Comunista (se estima que llegaron a constituirse unas 1500 JAP en Santiago); y, diversas experiencias de 
Abastecimiento Directo (Almacenes Populares, Comités de Abastecimiento Popular) que organizaban y distribuían una "canasta básica" de alimentos (Almacén Popular de Lo Hermida, ALMAC de Santa Julia, Comité de Abastecimiento Popular, CAP, en Villa Francia, etc.).

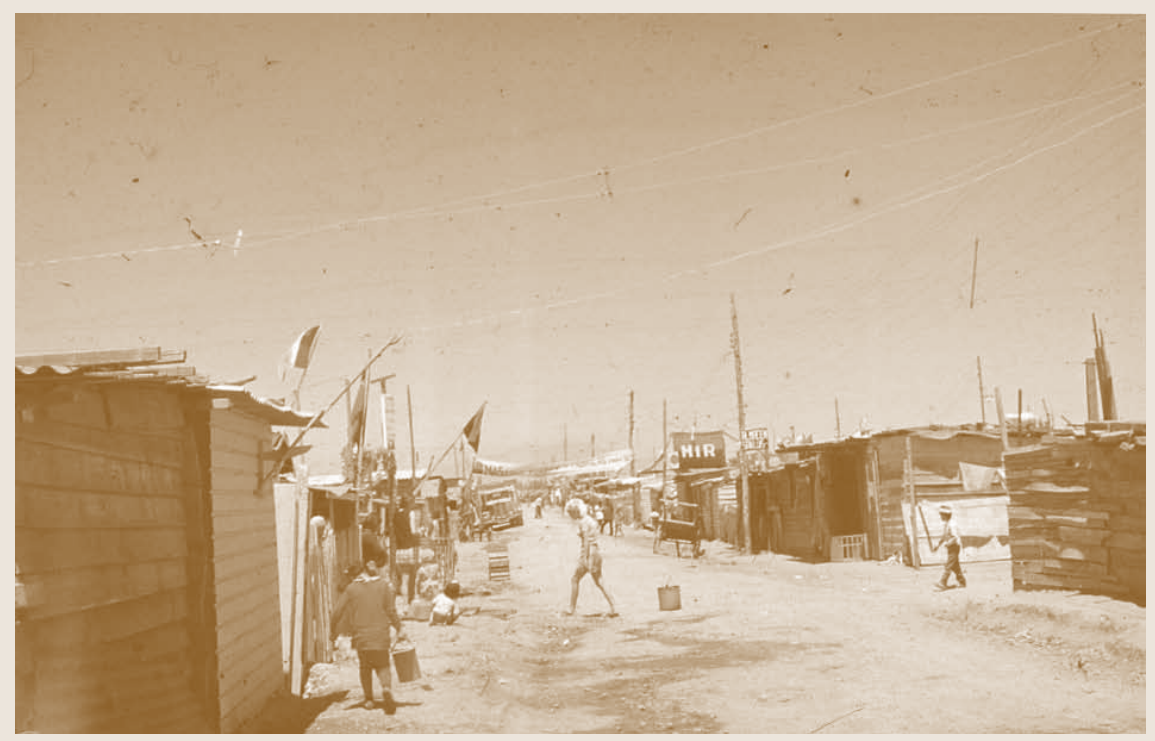

Campamento Nueva Habana, La Florida, Santiago.

\section{LOS ALIADOS: LAS RELACIONES CON LOS PARTIDOS POLÍTICOS}

Ciertamente, en una primera evaluación, los partidos políticos, tanto la Democracia Cristiana como la izquierda política (PC, PS, MIR) en distintas etapas y coyunturas, fueron aliados y apoyos fundamentales para el movimiento de pobladores. Lo fueron, en particular, como apoyo "organizativo", aspecto que en general es muy valorado por los pobladores. Sin embargo, este apoyo varió según se modificaban los lineamientos políticos de los partidos, por ejemplo el PC, que estimuló la organización de comités de Sin Casa y las "tomas" en los sesenta, se mostró contrario a lo que denominó "tomas indiscriminadas" durante la Unidad Popular. Para el PS y el MIR, por su parte, las tomas no eran contradictorias con el "gobierno popular".

Un segundo aspecto, que dio lugar a diversos debates políticos y académicos, eran el rol y el lugar que los pobladores debían jugar en el "pro- 
ceso revolucionario" . Para el PC, se trataba de articular las demandas de los pobladores con la política del gobierno: "No estamos en contra de las tomas de terreno como forma general de lucha (...) Sin embargo, bajo las condiciones del Gobierno Popular, somos partidarios, de poner el acento, no en este tipo de acciones, sino que en la búsqueda de soluciones (...) que conjuguen el esfuerzo de los organismos estatales y pobladores para enfrentar cualquier situación de emergencia habitacional" (Cantero, 1972). Por su parte, para el MIR, los pobladores debían ganar en autonomía y generar nuevas formas de "poder popular". Se trataba "de levantar Consejos Comunales de Trabajadores, donde los pobladores, obreros, campesinos y estudiantes se unan, se incorporen a la lucha, levanten un programa común" (Enríquez, 1972). Un tercer aspecto, también variable, fueron las formas de organización, que estimularon los partidos, en particular el Movimiento de Izquierda Revolucionaria, que en una primera etapa promovió la formación de "Milicias populares", pero que en su mayor desarrollo evolucionó hacia la formación de "frentes", de salud, educación, recreación, construcción, vigilancia, etc. Es decir, terminó por primar el desarrollo de nuevas formas de organización de la propia población, que se empezaron a constituir en microespacios de participación y poder local.

Con todo, más allá de las diferencias y matices, los partidos políticos fueron un actor fundamental, que interactuaba con las propias organizaciones que se daban los pobladores.

\section{LOS CAMBIOS EN LAS PRINCIPALES CIUDADES CHILENAS Y EL SURGIMIENTO DE NUEVAS POBLACIONES}

Las movilizaciones de los pobladores, especialmente por viviendas, transformaron significativamente las principales ciudades del país, dando lugar a nuevos barrios y a un significativo número de nuevas "poblaciones", la denominación chilena de los barrios populares.

En la región de Valparaíso la movilización de pobladores influyó en el Estado para que se pusieran en marcha una diversidad de proyectos de mejoramiento urbano, en toda la región, en especial, ampliación de redes de agua potable y alumbrado público, amén de que fue necesario generar

\footnotetext{
${ }^{4}$ Este debate cruzó, a principios de los años setenta, la producción del Equipo de Análisis Poblacional del CIDU, que integraban Manuel Castells, M. Teresa Chadwick, Rosemond Cheetham, Antonieta Hirane, Santiago Quevedo, Teresa Rodríguez, Gastón Rojas, Jaime Rojas y Franz Vanadererschueren.
} 
políticas de emergencia para enfrentar los efectos del terremoto de julio de 1971. Por otra parte, desde el punto de vista de la creación de nuevas poblaciones y barrios populares, las principales zonas que se expandieron fueron el sector norte de Viña del Mar, en especial Achupallas, Santa Julia, Concón y Reñaca Alto. También se densificaron los pueblos y ciudades interiores de la Región, en particular, Quilpué, Limache, Quillota y La Calera.

La mayor cantidad de tomas de sitios, que ampliaron el sector norte de Viña del Mar, se produjo en los primeros meses de 1971. Un Informe de la Policía indicaba, a principios de marzo de este año, que se contabilizaban 12 predios tomados, algunos como producto de ocupaciones de pobladores y otros locales de empresas tomadas por sus trabajadores ( $L a$ Estrella de Valparaíso, 1971, p. 6). La toma más importante fue la del Fundo Santa Julia, que dio origen al emblemático Campamento "Salvador Allende" donde se estimaba llegaron a instalarse unas 800 familias (Galleguillos y Torrente, 1997) que sumaban 4 mil personas. Sin embargo, otro conjunto de tomas se consignaba en Viña del Mar y Valparaíso, en mayo de 1971, que indicaban que el número de familias en tomas ascendía a 9.342 y de este total 1.886 corresponderían a Valparaíso mientras que el mayor número se concentraba en Viña del Mar y sus alrededores (La Estrella de Valparaíso, 1971, p. 3):

En Concepción se terminó de constituir el Barrio Norte de esa ciudad y las tomas alcanzaron gran impacto en Talcahuano, Chiguayante, Dichato, Lirquén, Penco y Coronel. Todas estas localidades se expandieron, en esos años, como producto de la movilización de los pobladores. En la prensa local, en enero de 1972, se informaba de un conjunto de tomas de terreno en el nivel intercomunal, que sumaban 76 campamentos, en los que habitaban 2.678 familias $^{5}$. El detalle era el siguiente:

4 campamentos (Concepción -284 familias)

22 campamentos (Talcahuano -776 familias)

1 campamento (Tomé-sin número)

4 campamentos (Dichato - 124 familias)

20 campamentos (Lirquén y Penco - 652 familias)

22 campamentos (Chiguayante y Manquimávida - 722 familias)

1 campamento (Coronel - 92 familias)

1 campamento (San Pedro - 28 familias) (El Sur, 1972, pp. 1 y 14).

${ }^{5} \mathrm{Si}$ se acepta el promedio de la familia popular, que se estimaba en la época en 5,5 miembros, da un total de 14.729 personas. 
Por otra parte, un estudio referido a la ciudad de Concepción indica que los sectores más comprometidos por las "tomas" fueron la Costanera del río Bío-Bío; los faldeos del Cerro Caracol; Chiguayante; Barrio Norte; la ribera del río Andalién; y los cerros Chepe y la Cruz (Cabrera, Luengo y Rebolledo, 1995).

El caso de Santiago es, por cierto, paradigmático, no solo porque la transformación de la ciudad -con la construcción de nuevas poblacionesse inició a fines de los años 50 y principios de los años 60 , sino porque el Programa de Viviendas de la Unidad Popular centró su atención en la resolución de los movilizados "sin casa", que en 1971 la CORVI estimaba en 85 mil familias que vivían en Campamentos; otros 65 mil en "Operaciones Sitio"; y 10 mil que habían completado sus cuotas para postular a viviendas básicas ${ }^{6}$. Ello implicaba no solo iniciar la construcción de nuevas viviendas, sino "urbanizar" sitios, es decir, dotar de elementos básicos de infraestructura urbana a los más de 200 campamentos que se estimaba, en 1972, sumaban a aproximadamente medio millón de personas (Santa María, 1973a; Santa María, 1973b).

A partir de la revisión de diversas fuentes, entre otros informes técnicos de la CORVI, mensajes presidenciales, estudios del CIDU, mapas del MINVU, tesis de grado y postgrado, logramos establecer para Santiago, un registro de 273 "obras iniciadas", que estaban dando lugar a 180 nuevas poblaciones. Es decir, en el caso de Santiago, la presión de los pobladores y los planes de vivienda de la Unidad Popular, en particular el Plan de Emergencia de 1971, estaban transformando por completo el trazado urbano de Santiago, ampliando el radio de la ciudad al hacer crecer las comunas populares.

\section{CONCLUSIONES}

En los años sesenta, pero particularmente durante el gobierno de la Unidad Popular, los pobladores, que representaban a los grupos sociales más pobres de las principales ciudades del país, incrementaron la presión sobre el Estado, en un contexto de mayor apertura y de una mejor disposición de las agencias de gobierno para atender sus demandas. La acción colectiva de los pobladores encontró un soporte fundamental en el desarrollo de sus propias

\footnotetext{
${ }^{6}$ Declaraciones del Vicepresidente de la CORVI al diario Las Noticias de la Última Hora, Santiago, 2 de abril de 1971, p. 9.
} 
organizaciones así como en las alianzas con los partidos políticos, lo que tuvo como efecto una política de viviendas populares más activa de Estado.

Sin desconocer los aspectos críticos de la gestión de gobierno de la Unidad Popular y la crisis que vivió la sociedad chilena en aquellos años, los pobladores modificaron sus modos de habitar las ciudades y comenzaron a vivir en "poblaciones", la denominación que tomaron los nuevos barrios populares que transformaron las principales ciudades del país.

Desde el punto de vista histórico, la constitución de un vigoroso movimiento social de pobladores, representa un proceso relevante para la historia social chilena, en el sentido que marcó el ingreso a las luchas sociales y políticas de los pobres de la ciudad, proceso semejante al que estimuló la reforma agraria, que favoreció un mayor protagonismo de los grupos sociales pobres del mundo campesino En ambos casos, "la toma" de sitios o de predios agrícolas, fue una forma privilegiada de acción, que cambió el orden tradicional tanto del campo como de la ciudad. Significativamente, mientras el cambio en el mundo campesino transformó por completo la estructura agraria nacional, debilitándose en el mediano plazo el protagonismo campesino, en el caso de las ciudades, los pobladores siguieron jugando roles muy activos y fue en el mundo de las poblaciones donde se estructuró la mayor oposición a la dictadura militar que siguió a la Unidad Popular.

\section{REFERENCIAS}

Cabrera, C.; Luengo, S.; Rebolledo, J. (1995). Una aproximación histórica al estudio de los pobladores en Concepción: 1968-1973. Memoria para optar el título de profesor de Estado en Historia y Geografía. Departamento de Ciencias Históricas y Sociales. Universidad de Concepción.

Cantero, M. (1972). "Vivienda: Trabajo de masas". Principios, 144, 92-103.

Castells, M. (1973). “Movimiento de pobladores y lucha de clases". Eure, 7, 9-34.

Cofré, B. (2007). Campamento Nueva Habana: el MIR y el movimiento de pobladores, 1970-1973. Concepción: Ediciones Escaparate.

Cofré, B. (2011). El movimiento de pobladores en el Gran Santiago, 1970-1973. Tesis para optar al grado de Magíster en Historia, Universidad de Santiago de Chile.

CORVI (1972). CORVI en el centro de la construcción. Santiago: Ediciones Auca.

De Ramón, A. (2000). Santiago de Chile (1541-1991). Historia de una sociedad urbana. Santiago de Chile: Editorial Sudamericana.

Duque, J. y Pastrana, E. (1972). "La movilización reivindicativa urbana de los sectores populares en Chile: 1964-1972". Revista Latinoamericana de Ciencias Sociales, 4. 
Enríquez, M. (1972). Conferencia de prensa. En: Lo Hermida. La cara más fea del reformismo. Santiago: Ediciones El Rebelde.

Espinoza, V. (1988). Para una historia de los pobres de la ciudad. Santiago: Ediciones Sur.

Farías, G. (1989). "Lucha, vida, muerte y esperanza”. En Constructores de ciudad. Nueve historias del Primer Concurso de Historias de las Poblaciones. Santiago: Ediciones Sur.

Galleguillos, E. y Torrente, L. (1997). "Breve historia de la Población Glorias Navales: 'Construyendo una ilusión””. Última Década, 6, 195-225.

Garcés, M. (1998). Historia de la Comuna de Huechuraba. Memoria y oralidad urbana. Santiago: Ediciones ECO.

Garcés, M. (2002). Tomando su sitio. El movimiento de pobladores de Santiago, 1957-1970. Santiago: Lom Ediciones.

Halperin, T. (2008). Historia contemporánea de América Latina. 7a ed. Buenos Aires: Alianza Editorial.

La Estrella de Valparaíso, 12 de marzo de 1971, p. 6.

La Estrella de Valparaíso, 20 de mayo de 1971, p. 3.

Las Noticias de la Última Hora, Santiago, 1970-1973.

Leiva, S. (2002). "De la toma de terrenos a la toma del poder: El Campamento Nueva Habana y una nueva óptica para la movilización poblacional”. Revista de Historia Social y de las Mentalidades, 6, 109-123.

MINVU (Ministerio de la Vivienda y Urbanismo) (1972). Politica habitacional del Gobierno Popular. Programa 72. Santiago: Departamento de Publicaciones y Documentación.

Romero, J. L. (1999). Latinoamérica: Las ciudades y las ideas. Medellín, Colombia: Editorial Universidad de Antioquia.

Salazar, G. (2000). Peones, labradores y proletarios. Santiago: Lom Ediciones.

Santa María, I. (1973a). "Las tres vías en la historia del campamento chileno". Documento de trabajo. Santiago: Universidad Católica de Chile, Departamento de Urbanismo y Vivienda.

Santa María, I. (1973b). "El desarrollo urbano mediante 'asentamientos espontáneos': El caso de los campamentos chilenos”. Eure, 7, 103-112.

Servicio Nacional de Estadísticas y Censos (1952). Primer Censo Nacional de Viviendas. Santiago, Chile. 